\title{
FATORES QUE INFLUENCIAM NA EVASÃO DOS ALUNOS EM UM CURSO LIVRE
}

Andressa Sasaki Vasques Pacheco - EGC/UFSC - andressa.ufsc@ gmail.com

Kelly Cristina Benetti Tonani Tosta - EGC/UFSC - kellyadm@ hotmail.com

Patrícia de Sá Freire - EGC/UFSC - patriciasafreire@terra.com.br

Marina Keiko Nakayama - EGC/UFSC - marina@egc.ufsc.br

Fernando José Spanhol - EGC/UFSC - spanhol@led.ufsc.br

\section{RESUMO}

Este artigo tem como objetivo verificar quais são os principais fatores que influenciam na evasão dos estudantes dos cursos livres do CENED. Quanto a metodologia, caracteriza-se esta pesquisa como: descritiva, ex-post-facto, aplicada, estudo de caso e quantitativa. A coleta de dados deu-se por meio da aplicação de questionários com 36 alunos (20 concluintes e 16 evadidos). Identificou-se que entre os alunos que concluíram, acesso a computador e ou internet para estudo e a qualidade do curso a distância foram os fatores que mais contribuíram. O item que menos importa para este grupo é a Influência familiar. Já para os alunos que evadiram, destacam-se os encontros presenciais e o apoio da empresa que trabalha para fazer este curso. Também a influência familiar foi o menos votado. Comparativamente, percebe-se que para os dois grupos o tempo para estudar, a carga horária semanal de trabalho fora do curso, a situação econômica financeira, a adequação do conteúdo com o trabalho, a associação entre teoria e prática e o material didático oferecido são fatores importantes para se manterem no curso. Entretanto, há divergências em muitos fatores, o que representa que essa modalidade de ensino e esse modelo de curso não são adequados para qualquer pessoa.

Palavras-chaves: educação a distância. evasão. curso livre.

\section{FACTORS THAT INFLUENCE THE DROPOUT OF STUDENTS IN A FREE COURSE}

\section{ABSTRACT}

This article aims to determine which are the main factors influencing the dropout of CENED's free courses students. About the methodology, this research is characterized as descriptive, ex post facto, applied, case study and quantitative. The data collection took place through the application of questionnaires with 36 students (20 who finished and 16 who dropout). It was identified that among students who have completed the course, the access to computer and Internet to study and quality of the distance course were the main contributors. The less important item for this group is the family influence. For the students who dropout the presence meetings and the support of the company where they work to do this course are important. Also the family influence was the least voted. Comparatively, it is perceived that for the two groups, time to study, the weekly hours of work outside of the course, the financial and economic situation, the appropriateness of the content with the work, the association between theory and practice and teaching materials offered are important factors to accomplish the course. However, there are differences in many factors, what means that this type of education and model of course is not suitable for everyone.

Keywords: distance education. dropout. free course. 


\section{INTRODUÇÃ̃O}

De acordo com Belloni (2006), na sociedade da informação ou do saber, a formação inicial torna-se rapidamente insuficiente, então nesse contexto se apresenta a educação ao longo da vida, mais integrada ao local de trabalho e às necessidades do indivíduo. Sendo assim, mais do que a educação formal é requerida dos profissionais, visando a constante atualização em sua área de atuação.

Diante do advento das novas tecnologias e suas diversas possibilidades de uso, verifica-se que várias instituições estão começando a ofertar seus programas educacionais a distância. No entanto, percebe-se que nem todas estão conseguindo obter resultados favoráveis, visto que muitos dos alunos que ingressam abandonam o curso antes de concluir.

Nesse contexto se faz importante estudar que fatores influenciam na permanência dos alunos dos cursos livres do Centro Nacional de Educação a Distância CENED, que oferece formação na área ambiental através da modalidade de Educação a Distância por meio da oferta de cursos livres.

\section{FUNDAMENTAÇÃO TEÓRICA}

Com a ampliação da competitividade entre as organizações, a busca por profissionais que realmente façam a diferença é cada vez maior. Isso tem feito com que as pessoas, cada vez mais, busquem estar atualizadas. Uma das formas disso ocorrer é o que se chama de educação ao longo da vida. É um campo novo que se abre e requer a contribuição, e especialmente, a sinergia entre o campo educacional e econômico no sentido de promover a criação de estruturas de formação continuada mais ligadas aos ambientes de trabalho (BELLONI, 2006).

"Isto significa que os sistemas de educação terão necessariamente que expandir sua oferta de serviços, ampliando seus efetivos de estudantes em formação inicial e criando novas ofertas de formação continuada" (BELLONI, 2006, p. 6).

A principal forma utilizada para simultaneamente expandir a oferta de cursos e aproximar a educação do ambiente de trabalho é a educação a distância, facilitada com a ampla utilização das tecnologias da informação e comunicação.

Contudo, tem-se percebido que na mesma proporção em que aumenta a quantidade de cursos oferecidos e de pessoas que se matriculam, aumenta também a evasão. Por isso, trata-se nesse capítulo dos temas educação a distância e evasão.

\subsection{Educação a distância}

A tecnologia, aliada à globalização, é uma das principais causas desse novo paradigma da educação, criando novas possibilidades de dinâmicas de informação e comunicação. A educação a distância, a cada dia, ganha novos adeptos, com o desenvolvimento de novas formas de comunicação, tornando possível a metodologia de ensino em lugares e tempos distintos.

Muitas são as definições possíveis e apresentadas, mas há um consenso mínimo em torno da idéia de que EAD é a modalidade de educação em que as atividades de ensino-aprendizagem são desenvolvidas majoritariamente (e em bom número de casos exclusivamente) sem que alunos e professores estejam presentes simultaneamente no mesmo lugar (ABED, 2006).

De acordo com Moore e Kearsley (1996, p. 2) a EaD pode ser entendida como: 
A educação a distância é o aprendizado planejado que normalmente ocorre em diferentes locais através do ensino e os resultados provém de técnicas especiais no design do curso, técnicas instrucionais especiais, métodos especiais de comunicação através da eletrônica, bem como uma organização especial e arranjos administrativos.

Nesse sentido, a EAD apresenta-se como um importante instrumento de intercâmbio e articulação de conhecimento e informações entre diferentes comunidades virtuais de aprendizagem, o que demonstra ser um grande potencial pedagógico.

A evolução das mídias eletrônicas pode ser considerada uma das maiores responsáveis pela maximização do uso de sistemas de EAD. Visto que o atendimento ao aluno tornou-se possível em qualquer localidade do mundo, desde que este tenha como acessar a tecnologia e, principalmente, em "tempo real", a utilização da EAD em programas educacionais vem aumentando consideravelmente com o passar dos anos.

\subsection{Evasão}

Costa (apud BIAZUS, 2004) apresenta como conceito de evasão definitiva a saída terminante do curso, ou seja, é aquela pela qual o aluno se afasta da instituição, por abandono, desistência definitiva do curso ou transferência para outra instituição.

Quanto ao cenário nacional, a pesquisa do Anuário Brasileiro Estatístico de Educação Aberta e a distância - ABRAEAD - (2007) aponta algumas informações sobre a evasão em EaD no Brasil. Quanto aos fatores que influenciaram na evasão deste aluno destaca-se: falta de tempo e situação financeira que não permitiu continuar o curso. Também cabe destacar que muitos alunos se surpreendem com a consistência dos cursos, pois há uma sensação, geralmente frustrada, que os cursos a distância são mais fáceis que os presenciais (ABRAEAD, 2007).

Em relação aos fatores que influenciam na evasão dos alunos, observou-se vários estudos, tomando-se como base o proposto por Biazus (2004), que apresenta um Instrumento das Causas da Evasão.

Esse modelo foi adaptado por Pacheco (2007) considerando o estado da arte, bem como depoimentos recolhidos de alunos evadidos do curso de graduação em Administração da UFSC na modalidade a distância. Esse estudo baseia-se, portanto, na replicação dos estudos de Pacheco (2007) em cursos livres.

Tem-se assim, o quadro com as categorias e seus respectivos indicadores a seguir:

\begin{tabular}{|l|l|}
\hline CATEGORIAS EXTERNAS & CATEGORIAS INTERNAS \\
\hline Sócio Políticos Econômicos & \\
\hline Apoio da empresa que trabalha para fazer este curso & Atitude comportamental \\
\hline Valorização do diploma no mercado de trabalho & Didática dos professores \\
\hline Tempo para estudar & Orientação da Coordenação do curso \\
\hline Carga horária Semanal de trabalho & Motivação e incentivo por parte do tutor \\
\hline Deslocamento ao pólo de ensino & Relacionamento com o tutor \\
\hline Acesso a computador e ou internet para estudo & Contato com professores \\
\hline Compreensão das matérias & \\
\hline Adequação do conteúdo com o trabalho & Motivos institucionais \\
\hline & Ausência de tutores nos pólos \\
\hline Vocação Pessoal & Acesso a bibliotecas \\
\hline Aptidão para a profissão & Estrutura dos pólos de ensino \\
\hline Possuir outro curso superior & Laboratório de informática nos pólos de ensino \\
\hline Adaptação ao sistema universitário & $\begin{array}{l}\text { Interatividade do ambiente } \\
\text { aprendizagem }\end{array}$ \\
\hline Mudança de interesse pessoal ou profissional & de \\
\hline
\end{tabular}




\begin{tabular}{|l|l|}
\hline Estar cursando paralelamente outro curso & Requisitos didáticos pedagógicos \\
\hline $\begin{array}{l}\text { Desconhecimento prévio a respeito do curso de } \\
\text { administração a distância }\end{array}$ & Carga horária curricular do curso \\
\hline & Relação do Currículo com o mercado de trabalho \\
\hline Características Individuais & Critérios de avaliação do aluno \\
\hline Problemas de Saúde & Associação entre a teoria e a prática \\
\hline Atendimento do curso às expectativas prévias & Relação entre conteúdos das disciplinas \\
\hline Adaptação a modalidade a distância & Encontros presenciais \\
\hline & Grau de dificuldade dos exercícios e provas \\
\hline 1.4 Conjunturais & Contato entre colegas de cursos \\
\hline Situação econômica financeira & Reprovação em mais de duas disciplinas no semestre \\
\hline Influência familiar & Prazos de entrega das atividades \\
\hline Mudança de residência ou cidade & Avaliação dos exercícios \\
\hline Mudança de estado civil & Avaliações das provas \\
\hline Responsabilidade econômica no sustento da família & Material didático oferecido \\
\hline & Qualidade do curso de administração a distância \\
\hline
\end{tabular}

Quadro 1: Categorias de análise da evasão

Fonte: adaptado de Biazus (2004)

\section{METODOLOGIA}

Quanto ao tipo de estudo, caracteriza-se como descritiva, ex-post-facto, aplicada e estudo de caso. Em relação a abordagem desta pesquisa, classifica-se como predominante quantitativa.

A amostra, qualificada pelos critérios objetivos de seleção dos indivíduos, foi definida por acessibilidade na empresa Centro Nacional de Ensino à Distância, que tem sede no Rio Grande do Sul, e desde 2002 oferece doze diferentes tipos de cursos livres a distancia na área de educação ambiental. Pela empresa já passaram, até a data de início da pesquisa, 898 (oitocentos e noventa e oito) alunos sob a tutoria de sete diferentes professores.

Como técnicas de coleta de dados foram utilizadas questionários estruturados e semi estruturados. A empresa enviou o questionário desta pesquisa por meio eletrônico diretamente para seus ex-alunos e estes, no prazo de dois meses, retornaram por meio eletrônico diretamente a um dos pesquisadores.

Foram enviados 898 questionários, incluindo todos os ex-alunos do Centro Nacional de Ensino a Distância - CENED/RS. Cinqüenta (50) e-mails retornaram por "erro" de endereço, e noventa e dois (92) foram respondidos, sendo setenta e seis (76) de alunos que completaram o curso e dezesseis (16) que não completaram. Dos respondentes que completaram o curso (76), configurou-se como amostra apenas vinte (20) deles. Os demais foram descartados por terem preenchido incorreta e incompletamente o questionário. Configura-se então como amostra final desta pesquisa, dezesseis (16) ex-alunos que não completaram nenhum curso e vinte (20) ex-alunos que completaram algum curso.

Com isso, por meio da utilização de uma escala de avaliação verbal, pode-se classificar os itens como:

a) para os alunos que concluíram o curso: não contribuiu para a conclusão do curso (1), contribuiu pouco para a conclusão do curso (2), contribui muito para a conclusão do curso (3) e contribuiu decisivamente para a conclusão do curso (4);

b) para os alunos que evadiram: não contribuiu para o abandono do curso (1), contribuiu pouco para o abandono do curso (2), contribui muito para o abandono do curso (3) e contribuiu decisivamente para o abandono ao curso (4). 
Após a coleta de dados vem a seção de tratamento. Os dados obtidos foram tratados estatisticamente através da análise descritiva, com a exposição de medidas como frequiência e média.

\section{RESULTADOS DA PESQUISA}

O CENED oferece cursos livres ligados à área de educação ambiental. Ao todo são 12 cursos oferecidos, com duração de 60 horas cada. As atividades são assíncronas, com exceção das teleconferências, realizadas semanalmente de maneira síncrona, mas que ficam gravadas para quem não teve a possibilidade de participar.

Tabulou-se e analisaram-se separadamente os questionários dos alunos que completaram o curso os quais formaram o Grupo 1 (Tabela 1). Da mesma maneira agruparam-se os alunos que não completaram o curso à distância, tabulando e analisando suas respostas como Grupo 2 (Tabela 2).

\subsection{Resultados do Grupo 1}

Para este grupo independente da média alcançada, vale destacar que os dois quesitos que mais importam para completarem o curso são o Acesso a computador e ou internet para estudo e, a Qualidade do curso a distância, visto a maior concentração de concordância nas duas afirmativas (27,78\% dos respondentes).

Para o grupo de alunos que completaram o curso, cumprindo com suas obrigações de realização de tarefas, apresentação do trabalho final do curso e por isso recebendo o certificado de participação o item que mais colabora para que fossem capazes de completar os cursos foi, com 50\% dos respondentes concordando totalmente ou parcialmente, a responsabilidade econômica no sustento da família $(2,33)$. Em seguida aparece o item Tempo para estudar $(2,33)$ com $44,44 \%$ das respostas.

Alcançando a mesma média $(2,22)$, porém com desvio padrões diferenciados, os itens a Didática dos Professores (desvio padrão de 2,18) do Acesso a computador e ou internet para estudo ( desvio padrão de 2,29), Adequação do conteúdo com o trabalho ( desvio padrão de 1,66) e Carga horária Semanal de trabalho fora do curso $(1,50)$, tem praticamente a mesma importância para a maioria dos respondentes que completaram o curso.

Ainda acima da média aparece a associação entre a teoria apresentada no curso e ainda a prática vivenciada pelo aluno $(2,17)$, e alto desvio padrão onde $55,56 \%$ dos respondentes não acham este quesito importante para a conclusão. Estar cursando paralelamente outro curso também alcançou a média de 2,17, mas com baixo desvio padrão. O material didático oferecido $(2,11)$, o relacionamento com o tutor $(2,11)$ e a situação econômica financeira $(2,11)$ são importantes para os alunos se manterem no curso.

O Contato com professores, os Encontros presenciais e a Valorização do diploma no mercado de trabalho foram apontados como incentivo a se manterem até o fim (média de 2,06). Com a mesma media $(2,00)$ aparecem as afirmativas Adaptação ao sistema de estudos diferenciado, Avaliações das trabalhos/provas, Contato entre colegas de cursos e Exigências de Conhecimentos Anteriores. Sendo os dois últimos com alto desvio padrão 2,29 (44,44\% não concordam) e 2,60 (50\% não concordam) respectivamente. A Interatividade do ambiente virtual de ensino-aprendizagem também alcançou a média de 2,00 . 
Na média, ou próximo dela se encontram vinte e quatro (24) itens que por falta de espaço e por não ter significância para o alcance dos objetivos desta pesquisa, não serão aqui especificados.

Pouco significativos para a manutenção dos alunos no curso se encontram os quesitos Aptidão para a profissão $(1,61)$, Mudança de estado civil $(1,61)$, Carga horária curricular do curso $(1,56)$, Mudança de residência ou cidade $(1,56)$. $O$ item que menos importa para este grupo é a Influência familiar $(1,39)$.

Tabela 1: Fatores que levam os alunos a concluir o curso.

\begin{tabular}{|c|c|c|c|c|c|c|}
\hline \multirow[b]{2}{*}{ ITENS DE ANÁLISE } & \multicolumn{6}{|c|}{ TABELA 1: Alunos que SIM completaram o curso } \\
\hline & \begin{tabular}{|c|} 
média \\
$\sqrt{1,94}$
\end{tabular} & $\begin{array}{l}\text { desvio } \\
\text { padrão }\end{array}$ & 1 & 2 & 3 & 4 \\
\hline Didática dos professores & 2,22 & 2,18 & $44,44 \%$ & $11,11 \%$ & $22,22 \%$ & $22,22 \%$ \\
\hline Orientação da Coordenação do curso & $\triangle 1,83$ & 2,87 & $50,00 \%$ & $27,78 \%$ & $11,11 \%$ & $11,11 \%$ \\
\hline Carga horária curricular do curso & 1,56 & 3,84 & $55,56 \%$ & $33,33 \%$ & $11,11 \%$ & - \\
\hline Relação do Currículo com o mercado de trabalho & $\triangle 1,83$ & 3,35 & $55,56 \%$ & $22,22 \%$ & $5,56 \%$ & $16,67 \%$ \\
\hline Critérios de avaliação do aluno & $\nabla 1,94$ & 2,69 & $33,33 \%$ & $38,89 \%$ & $27,78 \%$ & 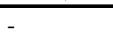 \\
\hline Apoio da empresa que trabalha para fazer este curso & 1,78 & 3,84 & $61,11 \%$ & $16,67 \%$ & $5,56 \%$ & $16,67 \%$ \\
\hline Valorização do diploma no mercado de trabalho & $\lesssim 2,06$ & 2,69 & $33,33 \%$ & $44,44 \%$ & $5,56 \%$ & $16,67 \%$ \\
\hline Situação econômica financeira & 1) 2,11 & 2,06 & $33,33 \%$ & $27,78 \%$ & $33,33 \%$ & $5,56 \%$ \\
\hline Aptidão para a profissão & 1,61 & 4,03 & $61,11 \%$ & $16,67 \%$ & $22,22 \%$ & - \\
\hline Exigências de Conhecimentos Anteriores & $\sum 2,00$ & 2,60 & $50,00 \%$ & $16,67 \%$ & $16,67 \%$ & $16,67 \%$ \\
\hline Adaptação ao sistema de estudos diferenciado & $\nabla 2,00$ & 2,18 & $38,89 \%$ & $27,78 \%$ & $27,78 \%$ & $5,56 \%$ \\
\hline Mudança de interesse pessoal ou profissional & $2 \sqrt{1,89}$ & 2,60 & $44,44 \%$ & $33,33 \%$ & $11,11 \%$ & $11,11 \%$ \\
\hline Estar cursando paralelamente outro curso & ن 2,17 & 1,80 & $27,78 \%$ & $38,89 \%$ & $22,22 \%$ & $11,11 \%$ \\
\hline Problemas de Saúde & $\triangle 1,78$ & 3,35 & $55,56 \%$ & $16,67 \%$ & $22,22 \%$ & $5,56 \%$ \\
\hline Influência familiar & 1,39 & 5,02 & $72,22 \%$ & $16,67 \%$ & $11,11 \%$ & - \\
\hline Mudança de residência ou cidade & \& 1,56 & 4,03 & $61,11 \%$ & $22,22 \%$ & $16,67 \%$ & - \\
\hline Atendimento do curso às expectativas prévias & $\sum 1,94$ & 2,69 & $50,00 \%$ & $22,22 \%$ & $11,11 \%$ & $\overline{16,67 \%}$ \\
\hline Associação entre a teoria e a prática & 1) 2,17 & 2,87 & $50,00 \%$ & $5,56 \%$ & $22,22 \%$ & $22,22 \%$ \\
\hline Adequação do conteúdo com o trabalho & 2,22 & 1,66 & $33,33 \%$ & $22,22 \%$ & $33,33 \%$ & $11,11 \%$ \\
\hline Tempo para estudar & 2,33 & 3,57 & $11,11 \%$ & $44,44 \%$ & $44,44 \%$ & - \\
\hline Carga horária Semanal de trabalho fora do curso & 2,22 & 1,50 & $27,78 \%$ & $33,33 \%$ & $27,78 \%$ & $11,11 \%$ \\
\hline Mudança de estado civil & 1,61 & 3,91 & $61,11 \%$ & $22,22 \%$ & $11,11 \%$ & $5,56 \%$ \\
\hline Responsabilidade econômica no sustento da família & 2,33 & 1,80 & $38,89 \%$ & $11,11 \%$ & $27,78 \%$ & $22,22 \%$ \\
\hline Motivação e incentivo por parte do tutor & $2 \sqrt{1,94}$ & 3,35 & $55,56 \%$ & $16,67 \%$ & $5,56 \%$ & $22,22 \%$ \\
\hline Encontros presenciais & $\sum \sqrt{2,06}$ & 2,69 & $33,33 \%$ & $44,44 \%$ & $5,56 \%$ & $16,67 \%$ \\
\hline Acesso a computador e ou internet para estudo & 2,22 & 2,29 & $44,44 \%$ & $16,67 \%$ & $11,11 \%$ & $27,78 \%$ \\
\hline Relacionamento com o tutor & 1) 2,11 & 2,06 & $44,44 \%$ & $16,67 \%$ & $22,22 \%$ & $16,67 \%$ \\
\hline Adaptação a modalidade a distância & $\triangle 1,78$ & 3,20 & $50,00 \%$ & $22,22 \%$ & $27,78 \%$ & - \\
\hline $\begin{array}{l}\text { Grau de dificuldade dos exercícios e trabalhos/provas do } \\
\text { curso }\end{array}$ & $\triangle 1,83$ & 2,69 & $44,44 \%$ & $33,33 \%$ & $16,67 \%$ & $5,56 \%$ \\
\hline Acesso a bibliotecas & $\nabla 1,89$ & 3,04 & $38,89 \%$ & $44,44 \%$ & $5,56 \%$ & $11,11 \%$ \\
\hline Contato entre colegas de cursos & 入 2,00 & 2,29 & $44,44 \%$ & $27,78 \%$ & $11,11 \%$ & $16,67 \%$ \\
\hline Contato com professores & $\sum 2,06$ & 2,06 & $44,44 \%$ & $22,22 \%$ & $16,67 \%$ & $16,67 \%$ \\
\hline Prazos de entrega das atividades & 1,67 & 3,84 & $55,56 \%$ & $33,33 \%$ & $0,00 \%$ & $11,11 \%$ \\
\hline Avaliação dos exercícios & $\triangle 1,83$ & 2,69 & $44,44 \%$ & $33,33 \%$ & $16,67 \%$ & $5,56 \%$ \\
\hline Avaliações das trabalhos/provas & $\nabla 2,00$ & 2,18 & $38,89 \%$ & $27,78 \%$ & $27,78 \%$ & $5,56 \%$ \\
\hline Interatividade do ambiente virtual de ensino-aprendizagem & $\nabla 2,00$ & 2,18 & $38,89 \%$ & $27,78 \%$ & $27,78 \%$ & $5,56 \%$ \\
\hline Material didático oferecido & 1) 2,11 & 2,60 & $44,44 \%$ & $11,11 \%$ & $33,33 \%$ & $11,11 \%$ \\
\hline Compreensão das matérias & $\sqrt{2,94}$ & 3,50 & $55,56 \%$ & $5,56 \%$ & $27,78 \%$ & $11,11 \%$ \\
\hline Meios de comunicação oferecidos para contato & $\triangle 1,83$ & 2,87 & $50,00 \%$ & $27,78 \%$ & $11,11 \%$ & $11,11 \%$ \\
\hline Qualidade do curso a distância & $\lesssim 1,94$ & 4,15 & $61,11 \%$ & $11,11 \%$ & & $27,78 \%$ \\
\hline
\end{tabular}

Fonte: dados primários.

\subsection{Resultados do Grupo 2}

Para este grupo independente da média alcançada, vale destacar que os dois quesitos que mais importam para abandonarem ou não o curso são Encontros presenciais (média de 2,50) e Apoio da empresa que trabalha para fazer este curso 
(média de 2,31), tendo tido com 31,25\% dos respondentes concordado plenamente com as afirmativas.

Além destes dois motivos, foram também apontados como importantes ter Tempo para estudar (2,75), Carga horária Semanal de trabalho fora do curso $(2,50)$ e Contato entre colegas de cursos $(2,50)$.

Tabela 2: Fatores que levam o aluno a abandonar o curso.

\begin{tabular}{|c|c|c|c|c|c|c|}
\hline \multirow[b]{2}{*}{ ITENS DE ANÁLISE } & \multicolumn{6}{|c|}{ TABELA 2: Alunos que NÃO completaram o curso } \\
\hline & \begin{tabular}{|c|} 
média \\
1,79 \\
\end{tabular} & $\begin{array}{c}\text { desvio } \\
\text { padrão }\end{array}$ & 1 & 2 & 3 & 4 \\
\hline Didática dos professores & $\triangle 1,69$ & 3,08 & $56,25 \%$ & $25,00 \%$ & $12,50 \%$ & $6,25 \%$ \\
\hline Orientação da Coordenação do curso & $\triangle 1,56$ & 3,67 & $56,25 \%$ & $37,50 \%$ & - & $6,25 \%$ \\
\hline Carga horária curricular do curso & $\triangle 1,69$ & 3,54 & $43,75 \%$ & $50,00 \%$ & - & $6,25 \%$ \\
\hline Relação do Currículo com o mercado de trabalho & $\triangle 1,50$ & 3,67 & $56,25 \%$ & $37,50 \%$ & $6,25 \%$ & - \\
\hline Critérios de avaliação do aluno & $\triangle 1,56$ & 3,54 & $50,00 \%$ & $43,75 \%$ & $6,25 \%$ & - \\
\hline Apoio da empresa que trabalha para fazer este curso & 2,31 & 2,12 & $43,75 \%$ & $12,50 \%$ & $12,50 \%$ & $31,25 \%$ \\
\hline Valorização do diploma no mercado de trabalho & $\triangle 1,75$ & 2,83 & $50,00 \%$ & $25,00 \%$ & $25,00 \%$ & - \\
\hline Situação econômica financeira & $\sum 2,25$ & 2,24 & $43,75 \%$ & $6,25 \%$ & $31,25 \%$ & $18,75 \%$ \\
\hline Aptidão para a profissão & Љ 1,25 & 5,24 & $81,25 \%$ & $12,50 \%$ & $6,25 \%$ & - \\
\hline Exigências de Conhecimentos Anteriores & \& 1,38 & 4,69 & $75,00 \%$ & $12,50 \%$ & $12,50 \%$ & - \\
\hline Adaptação ao sistema de estudos diferenciado & $\sum 2,25$ & 3,08 & $37,50 \%$ & $6,25 \%$ & $50,00 \%$ & $6,25 \%$ \\
\hline Mudança de interesse pessoal ou profissional & 1,31 & 5,24 & $81,25 \%$ & $12,50 \%$ & - & $6,25 \%$ \\
\hline Estar cursando paralelamente outro curso & $\triangle 1,44$ & 5,24 & $81,25 \%$ & $6,25 \%$ & - & $12,50 \%$ \\
\hline Problemas de Saúde & 1,25 & 5,79 & $87,50 \%$ & $6,25 \%$ & - & $6,25 \%$ \\
\hline Influência familiar & 及 1,25 & 5,24 & $81,25 \%$ & $12,50 \%$ & $6,25 \%$ & - \\
\hline Mudança de residência ou cidade & $\checkmark 1,31$ & 5,79 & $87,50 \%$ & - & $6,25 \%$ & $6,25 \%$ \\
\hline Atendimento do curso às expectativas prévias & $\backslash 2,00$ & 2,24 & $43,75 \%$ & $31,25 \%$ & $6,25 \%$ & $18,75 \%$ \\
\hline Associação entre a teoria e a prática & $\gg 2,19$ & 1,87 & $31,25 \%$ & $25,00 \%$ & $37,50 \%$ & $6,25 \%$ \\
\hline Adequação do conteúdo com o & $\unlhd 2,19$ & 1,87 & $25,00 \%$ & $37,50 \%$ & $31,25 \%$ & $6,25 \%$ \\
\hline Tempo para estudar & 个 2,75 & 1,41 & $12,50 \%$ & $25,00 \%$ & $37,50 \%$ & $25,00 \%$ \\
\hline Carga horária Semanal de trabalho fora do curso & ن 2,50 & 0,00 & $25,00 \%$ & $25,00 \%$ & $25,00 \%$ & $25,00 \%$ \\
\hline Mudança de estado civil & \& 1,00 & 6,93 & $100,00 \%$ & - & - & - \\
\hline Responsabilidade econômica no sustento da família & $\sqrt{7,06}$ & 6,36 & $93,75 \%$ & $6,25 \%$ & $0,00 \%$ & - \\
\hline Motivação e incentivo por parte do tutor & $\sum 1,88$ & 2,45 & $37,50 \%$ & $37,50 \%$ & $25,00 \%$ & - \\
\hline Encontros presenciais & $\widehat{~} 2,50$ & 1,87 & $37,50 \%$ & $6,25 \%$ & $25,00 \%$ & $31,25 \%$ \\
\hline Acesso a computador e ou internet para estudo & \& 1,25 & 4,90 & $75,00 \%$ & $25,00 \%$ & $0,00 \%$ & - \\
\hline Relacionamento com o tutor & $\triangle 1,44$ & 3,94 & $62,50 \%$ & $31,25 \%$ & $6,25 \%$ & - \\
\hline Adaptação a modalidade a di & $\gg 1,94$ & 2,55 & $31,25 \%$ & $43,75 \%$ & $25,00 \%$ & - \\
\hline $\begin{array}{l}\text { Grau de dificuldade dos exercícios e trabalhos/provas do } \\
\text { curso }\end{array}$ & $\triangle 1,50$ & 3,74 & $62,50 \%$ & $25,00 \%$ & $12,50 \%$ & - \\
\hline Acesso a bibliotecas & $\sum 2,06$ & 1,87 & $37,50 \%$ & $25,00 \%$ & $31,25 \%$ & $6,25 \%$ \\
\hline Contato entre colegas de cursos & ن 2,50 & 1,87 & $18,75 \%$ & $25,00 \%$ & $43,75 \%$ & $12,50 \%$ \\
\hline Contato com professores & $\sum 2,13$ & 2,55 & $31,25 \%$ & $25,00 \%$ & $43,75 \%$ & - \\
\hline Prazos de entrega das atividades & $\backslash 2,13$ & 2,12 & $25,00 \%$ & $43,75 \%$ & $25,00 \%$ & $6,25 \%$ \\
\hline Avaliação dos exercícios & $\triangle 1,56$ & 3,67 & $62,50 \%$ & $25,00 \%$ & $6,25 \%$ & $6,25 \%$ \\
\hline Avaliações das trabalhos/provas & $\triangle 1,63$ & 3,32 & $56,25 \%$ & $31,25 \%$ & $6,25 \%$ & $6,25 \%$ \\
\hline Interatividade do ambiente virtual de e & $\nabla 2,19$ & 1,87 & $25,00 \%$ & $43,75 \%$ & $18,75 \%$ & $12,50 \%$ \\
\hline Material didático oferecido & $\lambda 2,19$ & 1,22 & $37,50 \%$ & $25,00 \%$ & $18,75 \%$ & $18,75 \%$ \\
\hline Compreensão das matérias & $\triangle 1,69$ & 3,08 & $56,25 \%$ & $25,00 \%$ & $12,50 \%$ & $6,25 \%$ \\
\hline Meios de comunicação oferecidos para contato & $\backslash 1,88$ & 2,55 & $43,75 \%$ & $37,50 \%$ & $6,25 \%$ & $12,50 \%$ \\
\hline Qualidade do curso a distância & $\triangle 1,75$ & 2,83 & $50,00 \%$ & $25,00 \%$ & $25,00 \%$ & - \\
\hline
\end{tabular}

Fonte: dados primários.

Neste grupo, vinte e seis questões ficaram próximo da média e pelos mesmos motivos, falta de espaço e não interferir na análise dos resultados, não serão apresentados em detalhes neste artigo. 
Aqui também a influência familiar foi o menos votado (média de 1,39). Além dos Aptidão para a profissão (1,61), Mudança de estado civil $(1,61)$, Carga horária curricular do curso(1,56), Mudança de residência ou cidade $(1,56)$.

\subsection{Comparativo entre o Grupo 1 e o Grupo 2}

Visando alcançar os objetivos da pesquisa de levantar os principais motivos da evasão dos alunos de cursos livres a distância, procedeu-se a comparação entre os dois grupos - concluintes e evadidos.

Para melhor visualização do comparativo, montou-se uma tabela com os resultados dos questionários dos dois grupos, baseando a classificação nos resultados ordenados em ordem decrescente das médias alcançadas pelo Grupo 1.

Tabela 3: Comparativo entre alunos concluintes e evadidos.

\begin{tabular}{|c|c|c|}
\hline \multirow{2}{*}{ ITENS DE ANÁLISE } & Grupo 1 & Grupo 2 \\
\hline & $\Rightarrow 1,96$ & $\Rightarrow 1,79$ \\
\hline Tempo para estudar & 2,35 & 2,75 \\
\hline Responsabilidade econômica no sustento da família & 2,35 & 1,06 \\
\hline Carga horária Semanal de trabalho fora do curso & 2,25 & 2,50 \\
\hline Acesso a computador e ou internet para estudo & 2,25 & 1,25 \\
\hline Situação econômica financeira & 2,20 & 12,25 \\
\hline Adequação do conteúdo com o trabalho & 2,20 & 2,19 \\
\hline Didática dos professores & 2,20 & $\Rightarrow 1,69$ \\
\hline Associação entre a teoria e a prática & 2,15 & 2,19 \\
\hline Estar cursando paralelamente outro curso & 2,15 & 1,44 \\
\hline Material didático oferecido & 2,10 & 2,19 \\
\hline Valorização do diploma no mercado de trabalho & 2,10 & $\Rightarrow 1,75$ \\
\hline Relacionamento com o tutor & 2,10 & 1,44 \\
\hline Adaptação ao sistema de estudos diferenciado & 2,05 & 22,25 \\
\hline Interatividade do ambiente virtual de ensino-aprendizagem & $\Rightarrow 2,05$ & 2,19 \\
\hline Encontros presenciais & $\Rightarrow 2,00$ & 2,50 \\
\hline Contato com professores & $\Rightarrow 2,00$ & $\Rightarrow 2,13$ \\
\hline Motivação e incentivo por parte do tutor & 2,00 & $\Rightarrow 1,88$ \\
\hline Avaliações das trabalhos/provas & 2,00 & $\Rightarrow 1,63$ \\
\hline Apoio da empresa que trabalha para fazer este curso & $\Rightarrow 1,95$ & 2,31 \\
\hline Atendimento do curso às expectativas prévias & $\Rightarrow 1,95$ & $\Rightarrow 2,00$ \\
\hline Qualidade do curso a distância & $\Rightarrow 1,95$ & $\Rightarrow 1,75$ \\
\hline Compreensão das matérias & $\Rightarrow 1,95$ & $\Rightarrow 1,69$ \\
\hline Exigências de Conhecimentos Anteriores & $\Rightarrow 1,95$ & \&1,38 \\
\hline Contato entre colegas de cursos & $\Rightarrow 1,90$ & 2,50 \\
\hline Critérios de avaliação do aluno & $\Rightarrow 1,90$ & §1,56 \\
\hline Acesso a bibliotecas & $\Rightarrow 1,85$ & $\Rightarrow 2,06$ \\
\hline Adaptação a modalidade a distância & $\Rightarrow 1,85$ & $\Rightarrow 1,94$ \\
\hline Meios de comunicação oferecidos para contato & $\Rightarrow 1,85$ & $\Rightarrow 1,88$ \\
\hline Orientação da Coordenação do curso & $\Rightarrow 1,85$ & \&1,56 \\
\hline Avaliação dos exercícios & $\Rightarrow 1,85$ & >1,56 \\
\hline Relação do Currículo com o mercado de trabalho & $\Rightarrow 1,85$ & 1,50 \\
\hline Grau de dificuldade dos exercícios e trabalhos/provas do curso & $\Rightarrow 1,85$ & \1,50 \\
\hline Mudança de interesse pessoal ou profissional & $\Rightarrow 1,85$ & $\checkmark 1,31$ \\
\hline Problemas de Saúde & $\Rightarrow 1,85$ & 1,25 \\
\hline Prazos de entrega das atividades & 1,70 & $\Rightarrow 2,13$ \\
\hline Mudança de estado civil & $\sqrt{1,65}$ & 及1,00 \\
\hline Carga horária curricular do curso & $\checkmark 1,60$ & $\Rightarrow 1,69$ \\
\hline Mudança de residência ou cidade & $-1,60$ & \&1,31 \\
\hline Aptidão para a profissão & 81,60 & 1,25 \\
\hline Influência familiar & $\sqrt{1,45}$ & 及1,25 \\
\hline
\end{tabular}

Fonte: dados primários.

Percebe-se que para os dois grupos são fatores importantes para se manterem no curso:

- O tempo para estudar; 
- A carga horária semanal de trabalho fora do curso;

- A situação econômica financeira;

- Adequação do conteúdo com o trabalho;

- Associação entre teoria e prática e;

- O material didático oferecido.

Destacam-se os fatores que são importantes para os alunos que completaram o curso agrupados no Grupo 1, e que não são importantes para os alunos do Grupo 2:

- Responsabilidade econômica no sustento da família (Grupo 1 com média de 2,35 e, Grupo 2 com média de 1,06);

- O acesso ao computador e ou a internet para estudar (Grupo 1 com média de 2,25 e, Grupo 2 com média de 1,25);

- Estar cursando paralelamente outro curso (Grupo 1 com média de 2,15 e Grupo 2 com média de 1,44);

- Relacionamento com o tutor (Grupo 1 com média de 2,10 e o Grupo 2 com média de 1,44).

A Didática dos Professores, item de grande importância para o Grupo 1, ficou na média para o grupo 2. O mesmo acontecendo com o fator de valorização do diploma no mercado de trabalho.

Destaca-se também que, para os dois Grupo 1 e 2, ou seja tanto para o os alunos que completaram o curso como para os alunos que não completaram o curso, não importa os seguintes fatores:

- Mudança de estado civil;

- Mudança de residência ou cidade;

- Aptidão para a profissão;

- Influência familiar.

Para os alunos que completaram o curso, integrantes do Grupo 1, o prazo de entrega das atividades não conta como fator para mantê-los no curso bem como a carga horária curricular, porém para os alunos que não completaram o curso, estes dois quesitos importam.

Aponta-se nos resultados cinco itens de importância para os alunos que desistiram do cursos, que não são de grande importância para os alunos que completaram:

- Encontros presenciais ( Grupo 1 - média de 2,00 e Grupo 2 - média de 2,50);

- Contato entre colegas de cursos ( Grupo 1 - média de 1,90, Grupo 2 - média de 2,50)

- Apoio da empresa que trabalha para fazer este curso ( Grupo 1 - média de 1,95 e Grupo 2 - média de 2,31)

- Adaptação ao sistema de estudos diferenciado ( Grupo 1 - média de 2,05 e Grupo 2 - média de 2,25)

- Interatividade do ambiente virtual de ensino-aprendizagem ( Grupo 1 - média de 2,05 e Grupo 2 - média de 2,19)

\section{CONCLUSÃO}

A gerência e a administração eficiente requerem não apenas uma equipe competente, mas também sistemas e rotinas administrativas bem definidas e eficientes, além de sistemas de informação, planejamento e monitoramento (UNESCO, 1998).

Sendo assim, é importante que os cursos a distância criem ferramentas que possibilitem uma análise dos motivos que fazem com que os alunos abandonem os 
cursos, visando identificar oportunidades de melhoria, assim como conhecer fatores que contribuam para que o aluno conclua o curso, para que estes sejam fortalecidos.

Com este estudo identificou-se que entre os alunos que concluíram, acesso a computador e ou internet para estudo e a qualidade do curso a distância $(27,78 \%$ dos respondentes concordam) foram os fatores que mais contribuíram.

$\mathrm{Na}$ sequência, com maior média, com $50 \%$ dos respondentes concordando totalmente ou parcialmente, a responsabilidade econômica no sustento da família $(2,33)$. Em seguida aparece o item Tempo para estudar $(2,33)$ com $44,44 \%$ das respostas. O item que menos importa para este grupo é a Influência familiar (1,39).

Já para os alunos que evadiram, cabe destacar os Encontros presenciais (média de 2,50) e o Apoio da empresa que trabalha para fazer este curso (média de 2,31), tendo tido com $31,25 \%$ dos respondentes concordado plenamente com as afirmativas.

Também foram apontados como importantes ter Tempo para estudar $(2,75)$, Carga horária Semanal de trabalho fora do curso $(2,50)$ e Contato entre colegas de cursos $(2,50)$. Aqui também a influência familiar foi o menos votado (média de 1,39).

Comparativamente, percebe-se que para os dois grupos o tempo para estudar, a carga horária semanal de trabalho fora do curso, a situação econômica financeira, a adequação do conteúdo com o trabalho, a associação entre teoria e prática e o material didático oferecido são fatores importantes para se manterem no curso. Entretanto, há divergências em muitos fatores, o que representa que essa modalidade de ensino e esse modelo de curso não se adéqua para qualquer pessoa.

Isso se torna importante pois é preciso ter um perfil de aluno compatível com a modalidade, afim de se torna um fator crítico para o sucesso desse tipo de curso. Atrair a maior quantidade de alunos possível não garante que esses vão concluir, representando um alto desperdício de recursos e de esforço para esses alunos que desistem.

Por fim, ressalta-se que a evasão não deve ser somente encarada como um problema de custo, mas sim como também um problema social. Os aspectos qualitativos da aprendizagem e da aquisição de novos conhecimentos e habilidades são intangíveis, fazendo com que a perda advinda da evasão para as instituições e para a sociedade seja imensurável.

\section{REFERÊNCIAS}

ABRAED - Anuário Brasileiro Estatístico de Educação Aberta e a Distância. 3.ed. São Paulo: Instituto Monitor, 2007.

BELLONI, Maria Luiza. Educação a distância. 4. ed, Campinas: Autores Associados, 2006.

BIAZUS, Cleber Augusto. Sistema de fatores que influenciam o aluno a evadir-se dos cursos de graduação na UFSM e na UFSC: um estudo no curso de Ciências Contábeis. Florianópolis, 2004. Tese. (Doutorado em Engenharia de Produção). Universidade Federal de Santa Catarina.

MOORE, M. G; KEARSLEY, G. Distance education: a systems view. Wadsworth Publishing Company, 1996.

PACHECO, Andressa Sasaki Vasques. Evasão: análise da realidade do curso de graduação em Administração a distância da Universidade Federal de Santa Catarina. 2007. 136 f. Dissertação (Mestrado em Administração) - Programa de Pós-Graduação em Administração, Universidade Federal de Santa Catarina, Florianópolis, 2007.

UNESCO. Aprendizaje abierto y a distancia. Perspectivas y consideraciones políticas. Universidad Nacional de Educación a Distancia. Spain, 1998. 